Journal of Advanced Research in Fluid Mechanics and Thermal Sciences

Journal homepage: www.akademiabaru.com/arfmts.html ISSN: $2289-7879$

\title{
A Major Review on Tribology-Based Materials
}

\author{
Norazlianie Sazali ${ }^{1,2,}{ }^{*}$, Ahmad Shahir Jamaludin ${ }^{3}$, Nor Hasrul Akhmal Ngadiman ${ }^{4}$ \\ Faculty of Mechanical \& Automotive Technology Engineering, Universiti Malaysia Pahang, 26600 Pekan, Pahang, Malaysia \\ 2 Centre of Excellence for Advanced Research in Fluid Flow (CARIFF), Universiti Malaysia Pahang, Lebuhraya Tun Razak, 26300 Gambang, \\ Kuantan, Pahang, Malaysia \\ 3 Faculty of Manufacturing and Mechatronic Engineering Technology, Universiti Malaysia Pahang, 26600 Pekan, Pahang, Malaysia \\ 4 School of Mechanical Engineering, Faculty of Engineering, Universiti Teknologi Malaysia, 81310 Skudai, Johor Darul Takzim, Malaysia
}

\section{ARTICLE INFO}

\section{Article history:}

Received 4 December 2019 Received in revised form 13 March 2020 Accepted 15 March 2020

Available online 27 May 2020

Keywords:

Tribology; ceramic composites; polymer composites; friction and wear

\section{ABSTRACT}

\begin{abstract}
The utilization of advanced material in a diverse area can enhance the performance and quality of material engineering. Consequently, tribology testing becomes a demand in the industry such as construction, aviation, and automotive because of the widespread use of polymer-based natural fiber composites for their components and parts. This paper includes the discussion of each composites material that has different wear and sliding friction that required a different technique to encounter based on the ASTM standards by simulating under the real-time. The use of different materials demonstrates the wear and friction behavior and their potential for tribology engineering applications of the material are discussed in this review paper.
\end{abstract}

Copyright @ 2020 PENERBIT AKADEMIA BARU - All rights reserved

\section{Introduction}

Nowadays, the development of industry gives high impact and significant issues such as extensive natural resources. The growing sector, especially the large-scale construction and automation, causes a high impact on natural resources like metal and alloy. Therefore, another alternative must be focused on to substitute natural resources [1-3]. The use of composite seems promising due to its properties and characteristics as a substitute for the natural resource. The composite material has high corrosion resistance, high strength and the nature of composite material is adjustable based on a specific function [4-5]. The composite material defines as the two or more materials that have individual chemical and physical characteristic when combined produces $s$ new type of material which its characteristic is differ from the individual characteristic [6-7]. In other words, composites are solid comprised of reinforcement substances incorporated into its matrix, which helps to enhance the rigidity and strength. As a consequence, it will allow more massive structural load. Both types of

\footnotetext{
* Corresponding author.

E-mail address: azlianie@ump.edu.my (Norazlianie Sazali)
} 
matrix, either organic-based or inorganic act as support to maintain the reinforcement orientation [3,8-9]. The previous study by Yuan et al., [7] listed four benefits of using composite material compared to conventional which are they (composite material) has excellent tensile strength, produces a higher performance for the machine, reduce the life cycle cost and higher corrosion resistance.

The composite materials are divided based on four categories which are polymer matrix composites (PMCs), carbon-carbon composites (CCCs), metal matrix composites (MMCs) and ceramic matrix composites (CMCs). Each main group has different properties in term of their tribological, chemical, physical, and mechanical. The polymer matrix composites (PMCs) show the promising characteristic compared to another group. The PMCs material generally functions as a binder by transferring the stress to the filler and also have significantly high corrosion resistance characteristic, have lighter weight and is an organic solvent [10]. There are two types of filaments; inorganic and natural that usually employed to produce high modulus with excellent quality of polymer composites. Example for inorganic filament is from a glass while natural include aramid, polymer, carbon, and graphite [11-13]. Among them, glass is preferable due to simplicity (compared to carbon and aramid) and genuinely excellent mechanical properties [14-16]. In any case, these filaments have genuine disadvantage weight to quality proportion and its weakness. Contrast with glass fiber, regular fiber has less thickness and significant load to quality proportion. Therefore, for conventional fiberstrengthened polymer composite materials is developed in regard to their primary research and mechanical applications. Figure 1 shows the Metal Matrix Composites flow directions [17].

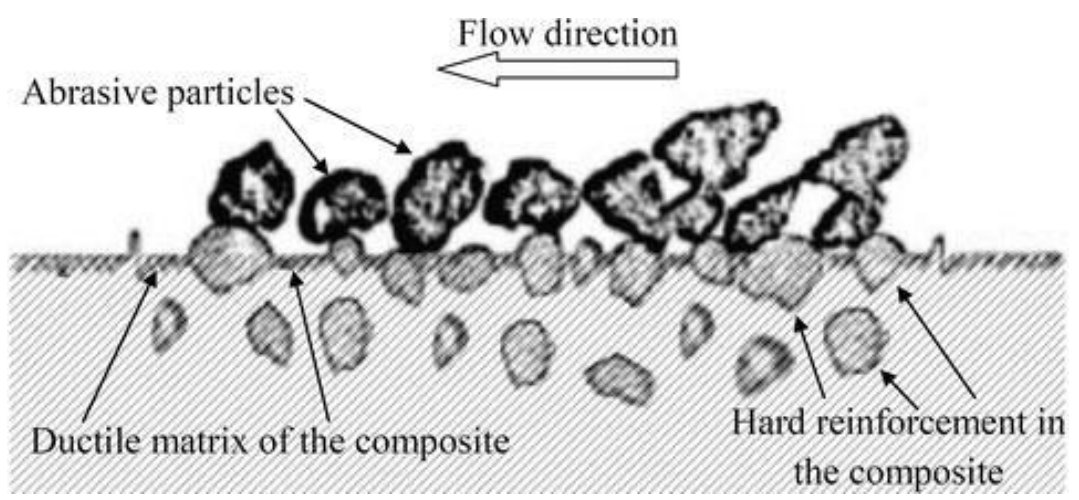

Fig. 1. Metal Matrix Composites flow directions [17]

\section{Material for Tribology's Application}

The polymers material needs to have similarity with tribo-properties to become effective alternatives for tribology materials. In recent year, there are numerous researches conducted and published by researcher related to the polymers and its friction characteristic [18-21]. Based on the research conducted, there is significant parameter which influenced the material characteristic of polymer towards friction which is the temperature. This parameter gives a considerable impact to maintain the mechanical properties of a polymer according to two aspects such as the temperature of rubbing component and the temperature of the friction interface. The relationship between temperature and mechanical properties of the polymer can be obtained based on the induction of thermal-oxidative degradation and the changer of material molecular structure and more [22]. Thus, the effect of temperature depends on the method of polymer process, the composition of the polymer, and the polymer molecular structure itself. A great effort is being done in order to create tribological composites from optional polymeric materials, specifically from the losses of multilayered film expended for bundling of different items [23-24]. In the meantime, the production of 
these wastage has caused a hazardous condition to the Mother Earth [25]. Lack of usage of wastage is one of the most significant obstacles that the advanced materials science has to face. Provisional investigations demonstrate that modification of auxiliary polymers with fillers of different inceptions empowers one to control the super-molecular structure, surface layer hardness, scattering of heat form by friction, and upkeep of self-grease conditions [26]. However, various problems of materials science remain unresolved that relate to the result of the composition, process, and performance parameters on the tribological properties such as composites; therefore, their broad application in friction units of machines and mechanisms is strongly inhibited. 2D materials commonly observed to have unconventional chemical, thermal, mechanical and electrical properties in which causing a lot of unusual frictional traits because of their unique planar structure (shown in Figure 2).

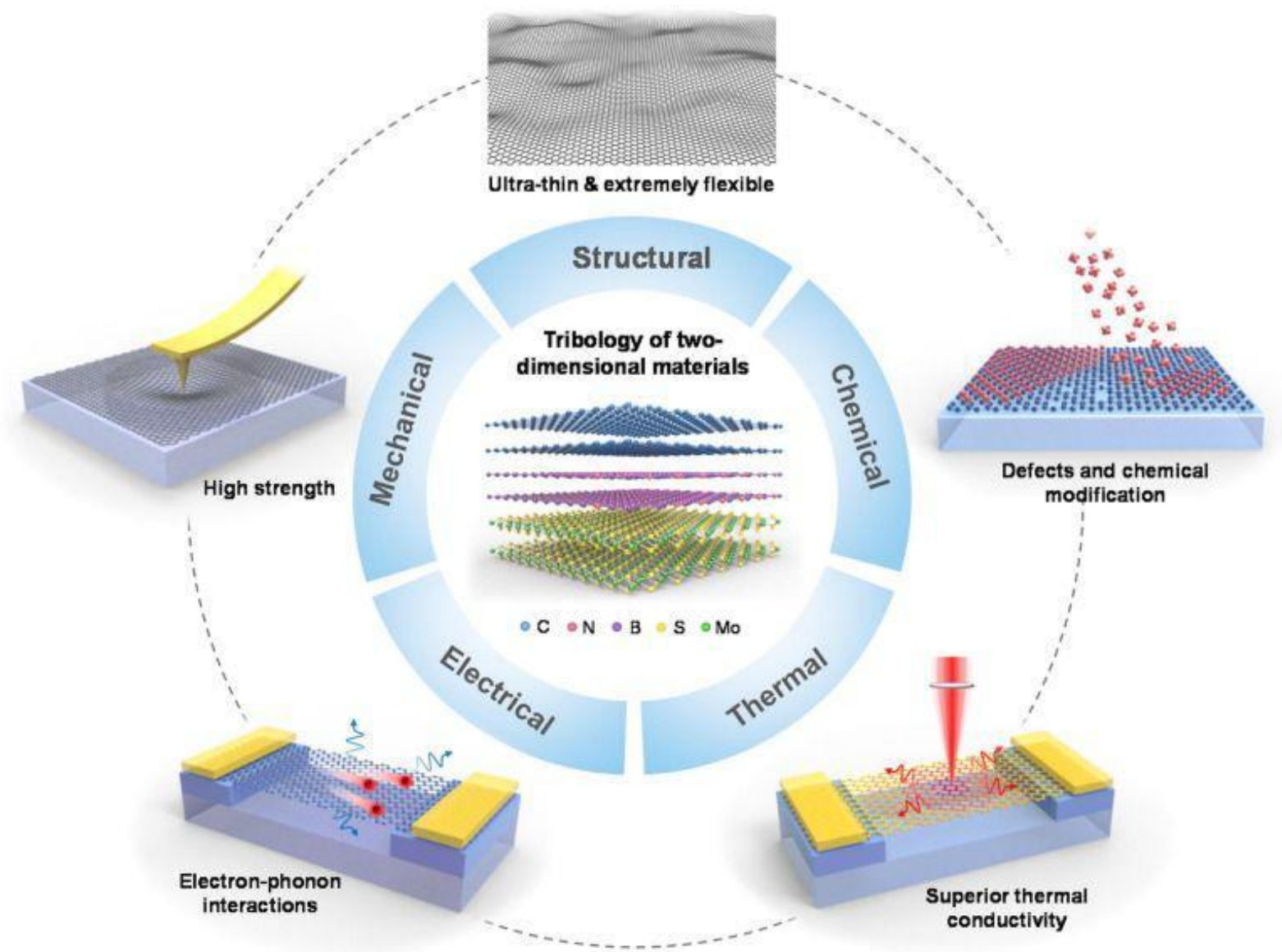

Fig. 2. Summary of two-dimensional materials features in terms of structure, electrical, chemical, mechanical and thermal that are related to tribological performance [20]

Currently, polymer composites are widely used in any application, including the component for structure application. The application of polymer composites as a component in engineering system must consider the wear condition of the material [8]. The wear can be explained as the interaction between the surface of the material that affects the service life of the component and reliability. The researches and improvements of wear resistance are essential because of it includes the service life of the material itself. The cost of wear is higher due to the direct cost wear replacement, the effect on increases in workload, decreases in productivity, as well as energy and environmental problem. It may seem that this problem is just a typical business problem, but wear can also be life-threatening if it is not handled well in no time soon. Even though wear has been widely studied, still, wear issues persisted in modern applications [26-27]. There are many terms to elaborate on different wear 
modes which can be divided into four; erosion, surface fatigue, adhesion, erosion and abrasion. Abrasive wear happens when surfaces of two materials contacted against each other and the harder molecule in one slice through the other. This type of wear becomes possibly the most critical factor when an extraneous movement causes material evacuation by simultaneous micro-ploughing and micro-cutting [28]. The adhesive wear is defined as the physical contact interaction between two surfaces and loses any of the surfaces after the contacting period. Figure 3 shows that continual deformations by these molecules can suppress material through micro-fracture, micro-cutting, pullout of accelerated fatigue or individual grains.

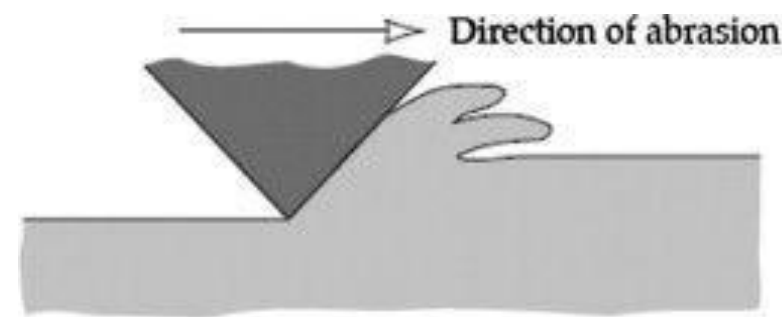

a) Cutting

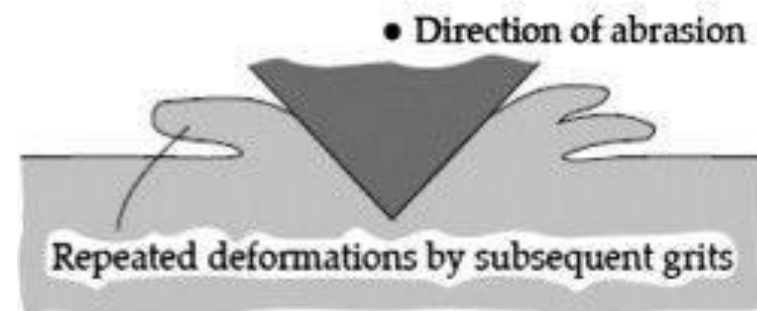

c) Fatigue by repeated ploughing

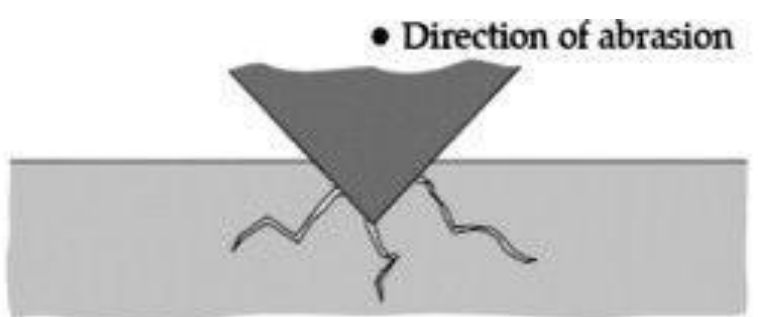

b) Fracture

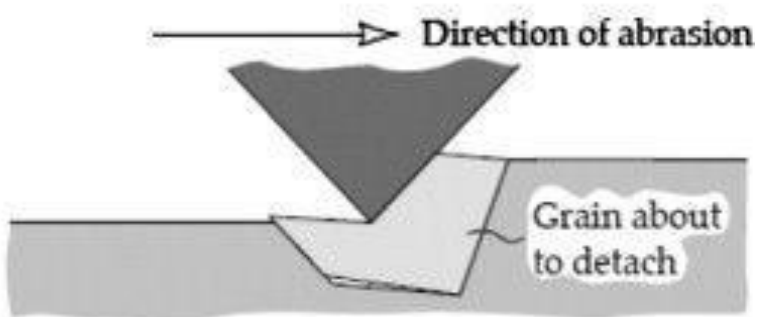

d) Grain pull-out

Fig. 3. Abrasive wear mechanisms: micro-cutting, fracture, fatigue and grain pull-out [29]

Additionally, the surface fatigue is defined as the type of wear that involves when the small particle become are removed from a surface by the crack on continued rolling or sliding superficially. The loss of material due to the wear occurs in a condition that there is mechanical interaction between that sturdy surface, either solid or liquid or both interactions [30]. Polymer and polymer composites are known as the significant material for tribology material and widely used in various industry due to their better tribology performance, and better friction and wear resistance compared to other materials. The polymer and its composites is are a better option as the tribology material because of their non-lubricated characteristic. These days much consideration is needed to investigate the firm molecule disintegration conduct of polymer composites because of their high potential utilization in various mechanical industry. Therefore, the parameter of erosion resistance become a crucial factor for the material selection and for the polymer composites itself. The research and study of erosion resistance characteristic are highly recommended. Each composite has different behaviour towards erosion due to the several factors such as type of material, percentage of mix, orientation properties of composites and the reinforcement. Therefore, the knowledge of the wear rate characteristic and the variable is significant to design and selection of material for any application with less wear rate [17,31-32].

The polymer has been known for their high mechanical properties, low cost of production, reduce waste, and the essential characteristic is the performance of polymer for tribology engineering [22]. There are only a few of polymers that have high tribological prerequisites; in any case, hybrid polymers or composite, polymers frequently have the benefit of low weight and high corrosion 
resistance compared to the other materials [33]. Tribological utilization of polymers includes various applications such as bearing components, building structures, aviation and spacecraft industry, home appliances, cushion, vehicle tires, and the brake pad cushion, and different kinds of surfaces for ideal haptic properties [27]. The tribological behaviour of polymers is based on three factors. First, the tribology behaviour based on the interaction between the surface, then the second factor is the load and force on the material itself, and the last element is the environment [19,34]. Based on the factor listed earlier, modifications to the polymer was done by incorporating the appropriate fillers to suit the specific applications to control the reaction occur. Hence, they are regularly utilized as a composite or in a mixed structure for ideal contact and wear execution [25]. Currently, polymer composites based on epoxy material seems to have expanded utilization in numerous applications, whereby an ideal mix of softness, phenomenal specific modulus, palatable warm and wear opposition has credited to their uses in various designing segments. As an example, in building, they were utilized as essential parts like substantial direction, while in-car trucks, they can fill in as multi-layer leaf springs. Whereas in the aeroplane industry, fan housings, airframes, floor loads up, helicopter rotor cutting edges and fairings have been employed from composites derived from epoxy [8].

Correspondingly, various fibrous reinforcement is available currently derived from natural and synthetic materials. The examples of synthetic materials are carbon, graphite, and glass while for instance, the natural resources are bamboo, sum hemp, and cotton. Both can be used individually or by having combination and correspond to the application. For instance, they are suitable for the application such as nuclear plant, chemical plant, and aerospace that required the high tensile strength and high structure stress [10]. Besides, they also can be mixed up into the complex shapes, corrosion resistance, high strength to weight ratio, excellent weathering properties even high thermal and electrical insulation [35]. Meanwhile, it can be used for boards and cladding in lower stress application. The glass fiber fortified PMCs go about as space-filling boards, supporting their weight yet not exposed to any substantial outside burdens. PMCs shows potential as tribo-materials due to the low-cost, low-density, high corrosion resistance, improve friction and wear resistance compared to others, reduce the waste and easy to fabricate [36]. Few utilizations of PMCs include as seals, low rubbing and wear gears, heading, brakes, tires, dental applications, turbine or pump blades, transport belts and hip substitutions in which the substitute material ought to possess low friction coefficient and moderate wear. To add, several mechanisms known to create friction are (1) adhesion, (2) mechanical interactions of surface asperities, (3) ploughing of one surface by asperities on the other, (4) surface fractures, also (5) deformation of local plastics done by third bodies, commonly agglomerated wear particles, trapped amid the moving surfaces (Figure 4).

Even though there is a reduction of particle size to the nano-scale, however, the performance of friction and wear rate are diverse from that micro-particle filled system [38]. The reduction occurs due to the decrease in angularity compared to micro-particles. The nano-filler also are capable to freely move in the contact area between the surfaces, becoming a gap between the surface and as the polishing agent that can reduce the wear and friction. Consequently, this led to a temperature decrease in that particular area [39]. Furthermore, this can produce high composite thermal conductivity that reduces the heat caused by the contact area of sliding material. The tribology properties seem to be great and better by using small particle compared to the more massive particle. Based on research conducted by Goyal and et al., [40], the study discovers that the minute particle of $\mathrm{SiC}$ (nano, micron, and whisker) type gives impact by decreases wear rate and friction when merging into PEEK matrix at a fixed filler capacity, for instance, $10 \mathrm{wt} \%$ ( $\sim 4$ vol\%). Furthermore, another research determines that the use of nano-size of filler advantage on the thin arrangement, uniform formation, and continuously transfer film [41]. The investigation used $\mathrm{ZrO}_{2}$ nanoparticles with different size from $10 \mathrm{~nm}-100 \mathrm{~nm}$ resulted in the effective reduction of wear and friction. On the 
other hand, the previous study shows that the improvement in reduction of friction and wear when the particles size was less than $15 \mathrm{~nm}$ which compared to the spherical filled epoxy that has a different size from $120 \mathrm{~nm}-510 \mathrm{~nm}$. Both results show the complementary trend, but the small size particle filler was far more effective for the composite wear resistance.
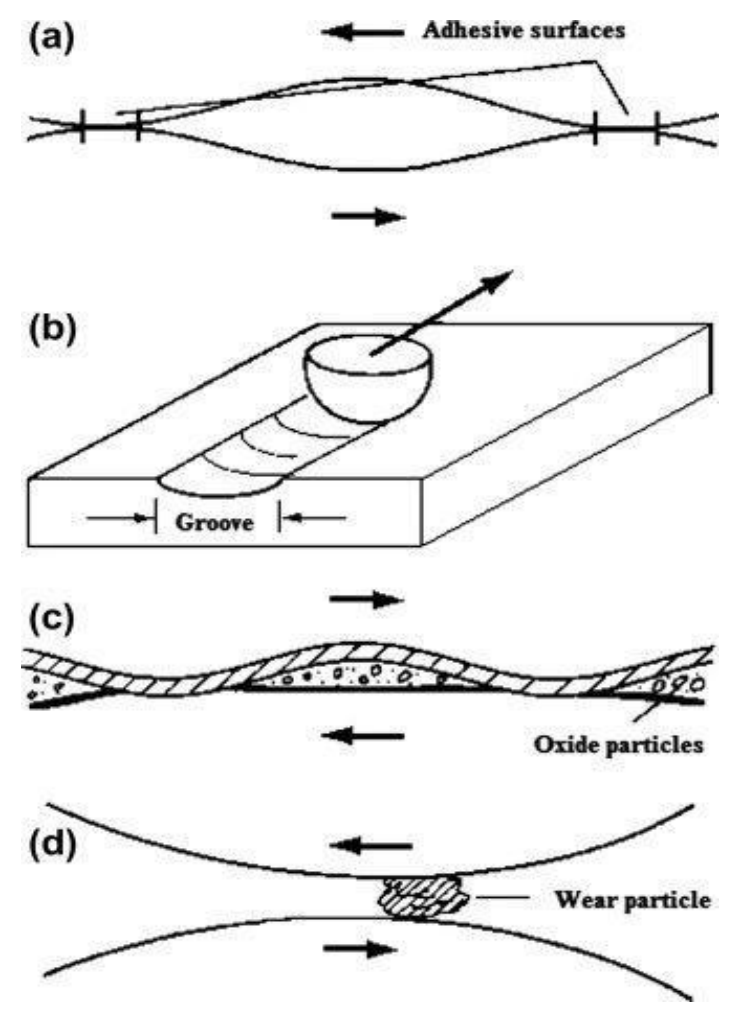

Fig. 4. Microscopic systems which generating the friction: (a) Adhesion, (b) ploughing, (c) oxides deformation and fracture, and (d) trapped wear particle [37]

In order to obtain polymer composite with high wear resistance characteristic, the only way is to investigate different functional filler, primarily their absorbing characteristic filler [8]. Up to this date, in any case, less effort has been coordinated to the hybrid composites improvement by joining inorganic nanoparticles and conventional fillers. One paper issued on a synergistic activity in the tribological using polyphenylene sulfide composites originated from nanosized copper oxide and short fibers, the most minimal steady-state wear rate is acquired with hybrid composites [42]. The previous study demonstrated the joining of nanoparticles and improved substance could build the friction and wear resistance of carbon texture composites [26,43-44]. The expanded composites surface mechanical properties, and high bonding performance of the transfer film created on the metallic counter faces give the beneficial impact of nanosized particles on the wear rate of the composites. This is a subsequent explicit shows that the combination of inorganic nanoparticles and conventional tribo-fillers becoming a polymer is capable of enhancing wear rate. With the purpose to ultimately advance the impact of nanoparticles, the investigations on their combined effect with conventional fillers are conducted by a previous researcher using various type of polymers such as polyamide 66 (PA 66), polyetherimide (PEI) and epoxy. Short carbon fiber (SCF) also two strong greases, PTFE and graphite, have been utilized as conventional tribo-fillers. The standard measurement of the SCF is around $14.5 \mathrm{~mm}$, and approximately $\sim 90 \mathrm{~mm}$ in length. The PTFE powders 
and the graphite flakes are about $4 \mathrm{~mm}$ and $20 \mathrm{~mm}$ individually. Inorganic $\mathrm{TiO}_{2}$ nanoparticles were added as additional fillers. These particles produced a mean diameter of 300nm [25,45-46].

Notwithstanding, chemical treatments can be used to solve the issues, for example, bleaching and alkali treatment [47-49]. For instance, the bleaching and alkali treatment will clean the natural fiber surface from any impurities and meantime; this will increase the fiber surface become rough [50]. There are many researches and investigations conducted in identifying the effect of the chemical treatment towards the natural fiber characteristic, especially on their interface adhesion. For instance, research conducted recently is to determine the impact of two types of chemical treatment (alkali treatment and acid treatment) on the mechanical properties, interface adhesion, also the surface of DPF (date palm fiber) using different $\mathrm{NaOH}$ concentration of $0.5-5 \%$ and $\mathrm{HCL}$ concentration of $0.3-1.6 \mathrm{~N}$ [51]. From the previous investigation, the chemical treatment using $\mathrm{NaOH}$ increases the DPF surface roughness, mechanical properties, and interface adhesion as the concentration increase due to the formation of the pore on the DPF surface. In the context of tensile strength, the DPF increase their tensile strength about 300\% compared to untreated DPF with only use low concentration about $1 \%$ of $\mathrm{NaOH}$. Too high concentration level for alkali treatment effect on the decreases of DPF strength properties [51]. Meanwhile, for acidic treatment using $\mathrm{HCL}$, the tensile strength of DPF can be reduced and damaged the DPF surface.

The effect of acidic treatment on DPF also similarly recorded by bamboo fibers [52]. The depth studied of improvement of polymer composites by using alkali treatment has been investigated by research on the factor influence such as temperature. The experiment outcome shows that the use of alkali treatment $(\mathrm{NaOH})$ under various temperature range causes the surface to be rougher, and allow a better separation process in removing wax, non-cellulosic materials, impurities and inorganic substance [52]. The hydrogen bond between oxygen and hydrogen become weaker when $\mathrm{NaOH}$ is applied to the fiber. Besides that, the effect of alkali treatment makes the fiber elongation increase to $38 \%$ and the tensile strength increase to $65 \%$ as the temperature increase. To figure out the interfacial shears of natural fiber, most of the research uses the single fiber fragmentation tests (SFFTs) in which this test was carried out by using sisal fiber with polyester in two conditions (untreated fiber and pre-treated fiber). The test decreases the size of fiber particle for pre-treated fiber likewise increase the tensile strength to $23 \%$ compared to untreated fiber [53]. Based on analysis after the test, there are more fiber come out from the untreated fiber compared to treated ones. As mentioned earlier, the tribology engineering is significant in various industry such as material and manufacturing industry especially in term of abrasive, adhesion, etc. Consequently, the strong fundamental for tribology behaviour is crucial to design and fabricate the structure and mechanical part. At the end of the day, knowledge of the tribological engineering of material such as fiber with polymer composites must be studied carefully with their mechanical properties [8]. There are few kinds of research published related to the effect of polymeric composites tribology with natural fiber.

As mentioned earlier, a distinct type of natural fiber effect the tribology behaviour of polymerbased fiber composites differently. The relationship between wear rate and friction with sliding distance are inversely proportional. Furthermore, when achieving a specific range, the steady-state will be made somehow not all cases pursuit similar trends, but still, there is a slight difference in the friction and wear rate behaviour. For instance, composites such as glass-polyester, pure polyester, cotton-polyester, and kenaf-polyester have improvement in their wear rate and friction during the steady-state because of longer time of surfaces rubbing in running stage [26,54-55]. However, some of the composites (sisal-polyester, betelnut-polyester, bamboo polyester, and coir-polyester) shows opposite result in which they have higher wear rate at the first stage, and then slowly reduced as the 
time of rubbing increase [56-58]. The opposites result occurs because of both surfaces undergo smoothening process during the rubbing method take place.

As the small the particles size, the great difficulty to be dispersed due to the strong bond and attraction between the particles that make them to have low shear force during the compounding process. This reality is relatable with the nanoparticle's filler and polymer. Generally, under the tribology behaviour, the polymer that is filled with nanoparticles has encountered breakdown and disintegrate of particles due to the loosened clusters of particles [59]. Also, this similar condition can happen when the coupling agent is applied. The reaction of coupling agent can only occur in the exterior of nanoparticles, which is the crumbled structure is maintained. This reaction can lead to any improvement, comparatively. A better and deep understanding of nanoparticles and their specific properties also characteristics for utilization, the study on another technique to breakdown nanoparticle agglomerates. The outcome of the investigation highlight in the future study should focus on the reinforcement of nanoparticle. Therefore, to construct this thought, there are several recommendations such as proposing the grafting polymer onto the surface (inside and outside of nanoparticle algometers) and modified nanoparticles using chemical agglomerates.

Inferable from the low atomic weight nature, the monomers can infiltrate into the agglomerated nanoparticles effectively also respond with the nanoparticles. The nanoparticle agglomerates which containing interstitial volume is mostly loaded up with macromolecular chains. Then, it causes the agglomerated nanoparticles to become isolated. The outside of the nanoparticles would likewise become 'hydro-carbon' because of the boost from hydrophobicity due to grafting polymers. Besides that, this improves the filler with matrix adhesion based on chemical bonding or the chain entanglement between the polymer (matrix polymer and grafting polymer). Also, nanoparticles are believed would be firmly connected to the matrix and effect on the reduction of friction and wear rate. The feasibility of this idea has been demonstrated by our previous work on nano-silica filled epoxy systems [26, 60-61]. In the meantime, the technique is an excellent method to increase the strength and toughness of thermo-plastics at low nano-filler loading [62-64].

\section{Conclusions}

Based on those researches conducted, several issues can be pointed out such as:

i. The wear and friction rate of the polymer-based fiber composite is changing according to the operation parameter.

ii. The use of chemical treatment such as alkali treatment and acid treatment influence the mechanical properties of polymer-based fiber composite, but according to the chemical type and concentration being used.

iii. The wear rate and friction were improved by using natural fiber for some cases and not for all polymer-based fiber composites. Therefore, further studied must be carried out.

iv. The use of lubricants leads to enhancement tribology behaviour (friction and wear rate performance) and the shear resistance in the interface zone.

v. There is a gap of difference between experiment and modelling mode, but by having the artificial neural networks modelling may tighten the gap between it.

\section{Acknowledgement}

The authors thanked the Ministry of Higher Education (MOHE) for financially supported this study through Fundamental Research Grant Scheme (FRGS/1/2018/TK10/UMP/02/1) - RDU190105, as well as Universiti Teknologi Malaysia (UTM) through Fundamental Research Grant Scheme (FRGS) funding number 5F188 and the Collaborative Research Grant (CRG) funding number 08G32. 


\section{References}

[1] Mannekote JK, Kailas SV, Venkatesh K, and Kathyayini N. "Environmentally friendly functional fluids from renewable and sustainable sources-A review." Renewable and Sustainable Energy Reviews 81 (2018): 1787-1801.

https://doi.org/10.1016/j.rser.2017.05.274

[2] Roy S, and Ragunath S. "Emerging Membrane Technologies for Water and Energy Sustainability: Future Prospects, Constrains and Challenges." Energies 11, no. 11 (2018): 2997.

https://doi.org/10.3390/en11112997

[3] Sazali N, Salleh WNW, Ismail AF, Wong KC, and Iwamoto Y. "Exploiting pyrolysis protocols on BTDA-TDI/MDI (P84) polyimide/nanocrystalline cellulose carbon membrane for gas separations." Journal of Applied Polymer Science 136, no. 1 (2019): 46901.

https://doi.org/10.1002/app.46901

[4] Sazali, N., W. N. W. Salleh, A. F. Ismail, N. A. H. M. Nordin, N. H. Ismail, M. A. Mohamed, F. Aziz, N. Yusof, and J. Jaafar. "Incorporation of thermally labile additives in carbon membrane development for superior gas permeation performance." Journal of Natural Gas Science and Engineering 49 (2018): 376-384. https://doi.org/10.1016/j.jngse.2017.10.026

[5] Tan YL, Huang CH, Guo ZX, and Yu J. "Morphology and Mechanical Properties of Polyamide 6/Polystyrene Blends Prepared by Diffusion and Subsequent Polymerization of Styrene in Polyamide 6 Pellets." Materials 11, no. 5 (2018): 776.

https://doi.org/10.3390/ma11050776

[6] Hou, Xiaowei, Zhenchao Liu, Yingcong Wei, Qi Zhao, Jinbiao Dong, Baijun Liu, Zhaoyan Sun, Tongfei Shi, Mingyao Zhang, and Wei Hu. "Proton conducting nanocomposite membranes of nanocellulose reinforced poly (arylene ether ketone) s containing sulfonic/carboxylic groups." Solid State lonics 311 (2017): 31-40. https://doi.org/10.1016/j.ssi.2017.08.019

[7] Yuan S, Shen F, Chua CK, and Zhou K. "Polymeric composites for powder-based additive manufacturing: Materials and applications." Progress in Polymer Science 91 (2019): 141-168.

https://doi.org/10.1016/i.progpolymsci.2018.11.001

[8] Friedrich K. "Polymer composites for tribological applications." Advanced Industrial and Engineering Polymer Research 1, no. 1 (2018): 3-39. https://doi.org/10.1016/i.aiepr.2018.05.001

[9] Shafie, Siti Nur Alwani, Wen Xuan Liew, Md Nordin, Nik Abdul Hadi, Muhammad Roil Bilad, Norazlianie Sazali, Zulfan Adi Putra, and Mohd Dzul Hakim Wirzal. "CO2-Philic [EMIM][Tf2N] Modified Silica in Mixed Matrix Membrane for High Performance CO2/CH4 Separation." Advances in Polymer Technology 2019 (2019): 1-10.

https://doi.org/10.1155/2019/2924961

[10] Kamaly N, Yameen B, Wu J, and Farokhzad OC. "Degradable Controlled-Release Polymers and Polymeric Nanoparticles: Mechanisms of Controlling Drug Release." Chemical Reviews 116, no. 4 (2016): 2602-2663. https://doi.org/10.1021/acs.chemrev.5b00346

[11] Shen Y, and Lua AC. "Structural and transport properties of BTDA-TDI/MDI co-polyimide (P84)-silica nanocomposite membranes for gas separation." Chemical Engineering Journal 188 (2012): 199-209. https://doi.org/10.1155/2019/2924961

[12] Feng C, Khulbe KC, Matsuura T, Farnood R, and Ismail AF. "Recent Progress in Zeolite/Zeotype Membranes." Journal of Membrane Science \& Research 1, no. 2 (2015): 49-72.

[13] Selim, Mohamed S., M. A. Shenashen, Sherif A. El-Safty, S. A. Higazy, Mahmoud M. Selim, H. Isago, and Ahmed Elmarakbi. "Recent progress in marine foul-release polymeric nanocomposite coatings." Progress in Materials Science 87 (2017): 1-32. https://doi.org/10.1016/i.pmatsci.2017.02.001

[14] Yampolskii Y. "Polymeric Gas Separation Membranes." Macromolecules 45, no. 8 (2012): 3298-3311. https://doi.org/10.1021/ma300213b

[15] Lau, Cher Hon, Phuc Tien Nguyen, Matthew R. Hill, Aaron W. Thornton, Kristina Konstas, Cara M. Doherty, Roger J. Mulder et al. "Ending aging in super glassy polymer membranes." Angewandte Chemie International Edition 53, no. 21 (2014): 5322-5326. https://doi.org/10.1002/anie.201402234

[16] Cangialosi, Daniele, Angel Alegria, and Juan Colmenero. "Effect of nanostructure on the thermal glass transition and physical aging in polymer materials." Progress in Polymer Science 54 (2016): 128-147. https://doi.org/10.1016/i.progpolymsci.2015.10.005

[17] Rohatgi, Pradeep K., Meysam Tabandeh-Khorshid, Emad Omrani, Michael R. Lovell, and Pradeep L. Menezes. "Tribology of metal matrix composites." In Tribology for scientists and engineers, pp. 233-268. Springer, New York, 
NY, 2013.

https://doi.org/10.1007/978-1-4614-1945-7 8

[18] Farfan-Cabrera, Leonardo Israel. "Tribology of electric vehicles: A review of critical components, current state and future improvement trends." Tribology International (2019).

https://doi.org/10.1016/i.triboint.2019.06.029

[19] Ranjan P, and Hiremath SS. "Role of textured tool in improving machining performance: A review." Journal of Manufacturing Processes 43 (2019): 47-73. https://doi.org/10.1016/i.jmapro.2019.04.011

[20] Zhang S, Ma T, Erdemir A, and Li Q. "Tribology of two-dimensional materials: From mechanisms to modulating strategies." Materials Today 26 (2019): 67-86. https://doi.org/10.1016/i.mattod.2018.12.002

[21] Zhu S, Cheng J, Qiao Z, and Yang J. "High temperature solid-lubricating materials: A review." Tribology International 133 (2019): 206-23. https://doi.org/10.1016/j.triboint.2018.12.037

[22] Wan S, Tieu AK, Xia Y, Zhu H, Tran BH, and Cui S. "An overview of inorganic polymer as potential lubricant additive for high temperature tribology." Tribology International 102 (2016): 620-35. https://doi.org/10.1016/i.triboint.2016.06.010

[23] E SF, Shi L, Guo ZG, and Liu WM. "The recent progress of tribological biomaterials." Biosurface and Biotribology 1, no. 2 (2015): 81-97. https://doi.org/10.1016/i.bsbt.2015.06.002

[24] Spear JC, Ewers BW, and Batteas JD. "2D-nanomaterials for controlling friction and wear at interfaces." Nano Today 10, no. 3 (2015): 301-14. https://doi.org/10.1016/i.nantod.2015.04.003

[25] Chan C-H, Tang SW, Mohd NK, Lim WH, Yeong SK, and Idris Z. "Tribological behavior of biolubricant base stocks and additives." Renewable and Sustainable Energy Reviews 93 (2018): 145-57. https://doi.org/10.1016/i.rser.2018.05.024

[26] Omrani E, Menezes PL, and Rohatgi PK. "State of the art on tribological behavior of polymer matrix composites reinforced with natural fibers in the green materials world." Engineering Science and Technology, an International Journal 19, no. 2 (2016): 717-36. https://doi.org/10.1016/i.jestch.2015.10.007

[27] Findik F. "Latest progress on tribological properties of industrial materials." Materials \& Design 57 (2014): $218-44$. https://doi.org/10.1016/j.matdes.2013.12.028

[28] Allen C, and Ball A. "A review of the performance of engineering materials under prevalent tribological and wear situations in South African industries." Tribology International 29, no. 2 (1996): 105-16. https://doi.org/10.1016/0301-679X(95)00073-D

[29] Stachowiak, Gwidon, and Andrew W. Batchelor. Engineering tribology. Butterworth-Heinemann, 2013.

[30] Codrington J, and Kotousov A. "A crack closure model of fatigue crack growth in plates of finite thickness under small-scale yielding conditions." Mechanics of Materials 41, no. 2 (2009): 165-73.

https://doi.org/10.1016/i.mechmat.2008.10.002

[31] Nunez EE, Gheisari R, and Polycarpou AA. "Tribology review of blended bulk polymers and their coatings for highload bearing applications." Tribology International 129 (2019): 92-111. https://doi.org/10.1016/i.triboint.2018.08.002

[32] Tyagi, Ankit, R. S. Walia, Qasim Murtaza, Shailesh M. Pandey, Pawan K. Tyagi, and Bharat Bajaj. "A critical review of diamond like carbon coating for wear resistance applications." International Journal of Refractory Metals and Hard Materials 78 (2019): 107-122. https://doi.org/10.1016/j.ijrmhm.2018.09.006

[33] Tzanakis, lakovos, Mark Hadfield, Ben Thomas, S. M. Noya, lan Henshaw, and S. Austen. "Future perspectives on sustainable tribology." Renewable and Sustainable Energy Reviews 16, no. 6 (2012): 4126-4140. https://doi.org/10.1016/j.rser.2012.02.064

[34] Lyu, Yezhe, Ellen Bergseth, Jens Wahlström, and Ulf Olofsson. "A pin-on-disc study on the tribology of cast iron, sinter and composite railway brake blocks at low temperatures." Wear 424 (2019): 48-52.

https://doi.org/10.1016/j.wear.2019.01.110

[35] Chen, Jyh-Ping, Pei-Ching Yang, Yunn-Hwa Ma, Su-Ju Tu, and Yu-Jen Lu. "Targeted delivery of tissue plasminogen activator by binding to silica-coated magnetic nanoparticle." International journal of nanomedicine 7 (2012): 5137. https://doi.org/10.2147/IJN.S36197

[36] Scholes, Colin A., and Ujjal K. Ghosh. "Review of membranes for helium separation and purification." Membranes 7 , no. 1 (2017): 9. 
https://doi.org/10.3390/membranes7010009

[37] Kennedy FE, Lu Y, and Baker I. "Contact temperatures and their influence on wear during pin-on-disk tribotesting." Tribology International 82 (2015): 534-42.

https://doi.org/10.1016/i.triboint.2013.10.022

[38] van Groenou AB. "Tribology of magnetic storage systems, a short review." Journal of Magnetism and Magnetic Materials 95, no. 3 (1991): 289-312. https://doi.org/10.1016/0304-8853(91)90226-Z

[39] Aydin, Mustafa, and Fehim Findik. "Wear properties of magnesium matrix composites reinforced with SiO2 particles." Industrial lubrication and tribology 62, no. 4 (2010). https://doi.org/10.1108/03687921080001504

[40] Goyal, R. K., A. N. Tiwari, U. P. Mulik, and Y. S. Negi. "Novel high performance Al2O3/poly (ether ether ketone) nanocomposites for electronics applications." Composites science and technology 67, no. 9 (2007): 1802-1812. https://doi.org/10.1016/j.compscitech.2006.10.020

[41] Chen P, Chen X, Chen X, An Z, and Kita H. "Pervaporation Separation and Catalysis Activity of Novel Zirconium Silicalite-1 Zeolite Membrane." Chinese Journal of Chemistry 27, no. 9 (2009): 1692-6. https://doi.org/10.1002/cjoc.200990284

[42] Hubička Z, Zlámal M, Čada M, Kment Š, and Krýsa J. "Photo-electrochemical stability of copper oxide photocathodes deposited by reactive high power impulse magnetron sputtering." Catalysis Today 328 (2019): 29-34. https://doi.org/10.1016/i.cattod.2018.11.034

[43] Zhai, Wenzheng, Narasimalu Srikanth, Ling Bing Kong, and Kun Zhou. "Carbon nanomaterials in tribology." Carbon 119 (2017): 150-171. https://doi.org/10.1016/i.carbon.2017.04.027

[44] Ali, Imran, Anastasia Kucherova, Nariman Memetov, Tatiana Pasko, Kirill Ovchinnikov, Vladimir Pershin, Denis Kuznetsov, Evgeny Galunin, Vladimir Grachev, and Alexey Tkachev. "Advances in carbon nanomaterials as lubricants modifiers." Journal of Molecular Liquids (2019): 251-66. https://doi.org/10.1016/i.molliq.2019.01.113

[45] Sundar, L. Syam, and Manoj K. Singh. "Convective heat transfer and friction factor correlations of nanofluid in a tube and with inserts: a review." Renewable and Sustainable Energy Reviews 20 (2013): 23-35.

https://doi.org/10.1016/j.rser.2012.11.041

[46] Ambreen T, and Kim MH. "Heat transfer and pressure drop correlations of nanofluids: A state of art review." Renewable and Sustainable Energy Reviews 91 (2018): 564-83.

https://doi.org/10.1016/j.rser.2018.03.108

[47] Zhuang GL, Wey MY, and Tseng HH. "The density and crystallinity properties of PPO-silica mixed-matrix membranes produced via the in situ sol-gel method for $\mathrm{H}_{2} / \mathrm{CO}_{2}$ separation. II: Effect of thermal annealing treatment." Chemical Engineering Research and Design 104 (2015): 319-32.

https://doi.org/10.1016/i.cherd.2015.08.020

[48] Ma, Chuan, Jie Yu, Ben Wang, Zijian Song, Jun Xiang, Song Hu, Sheng Su, and Lushi Sun. "Chemical recycling of brominated flame retarded plastics from e-waste for clean fuels production: a review." Renewable and Sustainable Energy Reviews 61 (2016): 433-450. https://doi.org/10.1016/i.rser.2016.04.020

[49] Sazali, N., W. N. W. Salleh, A. F. Ismail, N. H. Ismail, Mohamad Azuwa Mohamed, N. A. H. M. Nordin, M. N. M. M. Sokri, Y. Iwamoto, and S. Honda. "Enhanced gas separation performance using carbon membranes containing nanocrystalline cellulose and BTDA-TDI/MDI polyimide." Chemical Engineering Research and Design 140 (2018): 221-228. https://doi.org/10.1016/i.cherd.2018.09.039

[50] Ogundare SA, Moodley V, and van ZyI WE. "Nanocrystalline cellulose isolated from discarded cigarette filters." Carbohydrate Polymers 175 (2017): 273-81. https://doi.org/10.1016/i.carbpol.2017.08.008

[51] Alawar A, Hamed AM, and Al-Kaabi K. "Characterization of treated date palm tree fiber as composite reinforcement." Composites Part B: Engineering 40, no. 7 (2009): 601-6. https://doi.org/10.1016/i.compositesb.2009.04.018

[52] Wong, K. J., B. F. Yousif, and K. O. Low. "The effects of alkali treatment on the interfacial adhesion of bamboo fibres." Proceedings of the Institution of Mechanical Engineers, Part L: Journal of Materials: Design and Applications 224, no. 3 (2010): 139-148. https://doi.org/10.1243/14644207JMDA304

[53] Sawpan, Moyeenuddin A., Kim L. Pickering, and Alan Fernyhough. "Effect of various chemical treatments on the fibre structure and tensile properties of industrial hemp fibres." Composites Part A: Applied Science and 
Manufacturing 42, no. 8 (2011): 888-895.

https://doi.org/10.1016/i.compositesa.2011.03.008

[54] Soares, Rosane MD, Nataly M. Siqueira, Molamma P. Prabhakaram, and Seeram Ramakrishna. "Electrospinning and electrospray of bio-based and natural polymers for biomaterials development." Materials Science and Engineering: C 92 (2018): 969-982.

https://doi.org/10.1016/i.msec.2018.08.004

[55] Choi S-H, Sultan MM Ben, Alsuwailem AA, and Zuabi SM. "Preparation and characterization of multilayer thin-film composite hollow fiber membranes for helium extraction from its mixtures." Separation and Purification Technology 222 (2019): 152-61.

https://doi.org/10.1016/i.seppur.2019.04.036

[56] Quinzler D, and Mecking S. "Linear Semicrystalline Polyesters from Fatty Acids by Complete Feedstock Molecule Utilization." Angewandte Chemie International Edition 49, no. 25 (2010): 4306-8. https://doi.org/10.1002/anie.201001510

[57] Tachibana Y, Yamahata M, Ichihara H, and Kasuya K. "Biodegradability of polyesters comprising a bio-based monomer derived from furfural." Polymer Degradation and Stability 146 (2017): 121-5. https://doi.org/10.1016/j.polymdegradstab.2017.10.001

[58] Fakirov S. "Condensation Polymers: Their Chemical Peculiarities Offer Great Opportunities." Progress in Polymer Science 89 (2019): 1-18. https://doi.org/10.1016/i.progpolymsci.2018.09.003

[59] Darminesh, Sathuramalingam Pillay, Nor Azwadi Che Sidik, G. Najafi, Rizalman Mamat, Tan Lit Ken, and Yutaka Asako. "Recent development on biodegradable nanolubricant: a review." International Communications in Heat and Mass Transfer 86 (2017): 159-165.

https://doi.org/10.1016/i.icheatmasstransfer.2017.05.022

[60] Abdullah, K. F., and M. Z. Bahak. "The effect of fuel contamination on the wear characteristic of used motor oil." Journal of Advanced Research Design 5, no. 1 (2015): 10-16.

[61] Kumar, S., and K. Panneerselvam. "Optimization of friction and wear of nylon 6 and glass fiber reinforced (GFR) nylon 6 composites against 30 wt.\% GFR nylon 6 disc." Journal of Advanced Research in Materials Science 19, no. 1 (2016): 14-32.

[62] Sazali, N., W. N. W. Salleh, A. F. Ismail, K. C. Wong, and Y. Iwamoto. "Exploiting pyrolysis protocols on BTDA-TDI/MDI (P84) polyimide/nanocrystalline cellulose carbon membrane for gas separations." Journal of Applied Polymer Science 136, no. 1 (2019): 46901. https://doi.org/10.1002/app.46901

[63] Sazali, N., W. N. W. Salleh, A. F. Ismail, K. Kadirgama, F. E. C. Othman, and N. H. Ismail. "Impact of stabilization environment and heating rates on P84 co-polyimide/nanocrystaline cellulose carbon membrane for hydrogen enrichment." International Journal of Hydrogen Energy 44, no. 37 (2019): 20924-20932. https://doi.org/10.1016/i.ijhydene.2018.06.039

[64] Ismail, Nor Hafiza, Wan Norharyati Wan Salleh, Norazlianie Sazali, and Ahmad Fauzi Ismail. "The effect of polymer composition on $\mathrm{CO} 2 / \mathrm{CH} 4$ separation of supported carbon membrane." Chemical Engineering Transactions 45 (2015): 1465-1470. 